\title{
Adult Onset Still's Disease: A Case Report and Review of Literature
}

\author{
Fayaz Ahmad Sofi, M.D., Mohmad Hussain Mir, M.D., Mushtaq Ahmad Dangroo, M.D., Ghulam \\ Nabi Dhobi, M.D., Rafi Ahmed Jan, M.D., Sonaullah Shah, M.D., Sajad Rajab, M.D. \\ Department of Internal Medicine, Sher-i-Kashmir Institute of Medical Sciences, Soura Srinagar, Kashmir.
}

\section{A B S T R A C T}

Adult onset Still's disease (AOSD) is a rare rheumatic condition. It is characterized by diverse clinical and laboratory findings which may lead to errors in the differential diagnosis. Adult Still's disease is a diagnosis of exclusion. We describe herein a patient with Adult Still's disease, who presented with fever, rash and arthralgias. JMS 2012;15(2):176-79

Key words: Adult Still's disease, rash, arthralgias

Adult Still's disease or Adult onset Still's disease(AOSD) or Wissler-Fanconi syndrome is a rare inflammatory disorder of unknown etiology and pathogenesis. Its main features are high spiking fever, evanescent rash, polyarthralgia, lymphadenopathy, hepatosplenomegaly, leukocytosis, elevated liver enzymes, ESR and ferritin. ${ }^{1}$ The first description of an adult patient with signs and symptoms of Still's disease was in 1896. ${ }^{2}$ In 1971, Eric Bywaters described 14 adults with presentation similar to that of pediatric Still's disease, hence he used the term adult onset Still's disease. ${ }^{3,4}$

\section{Case report}

A 36 year old female, housewife, Para 2, Eumenorrhoeic presented to our department of Internal Medicine at SKIMS, a tertiary care hospital of our state, with complaints of fever, arthralgias and muscle aches and pains of 3 weeks

\section{Correspondence:}

Dr. Fayaz Ahmad Sofi

Associate Professor

Incharge Rheumatology Unit

Department of Internal Medicine

Shere-Kashmir Institute of Medical Sciences Srinagar Kashmir.

E-mail:fayazkanjwal@rediffmail.com duration in November 2009. The fever was high grade, intermittent, with a maximum spike of $41^{\circ} \mathrm{C}$ occurring especially during evening hours. There were no rigors or chills. The arthralgias were first noticed in small joints of hands and subsequently of wrists, elbows, ankles and knees. There was no morning stiffness or joint swellings or effusion. She also had vague muscle aches and pains all over body. During hospital stay, she complained of sore throat and development of an evanescent, non-pruritic, Solmon coloured rash was observed on trunk and limbs. The rash was transient and used to appear with spikes of fever. There was no history of headache, cough, sputum production, breathlessness, abdominal pain, dysuria, loose motions, vomiting, oral ulcers, blood transfusion, drug abuse or travel to malarial endemic area.

In past she was subjected to cholecystectomy for cholelithiasis in year 2001 and haemorrhoidectomy for bleeding piles in year 2003. Her family historywas insignificant.

Physical examination revealed mild pallor, small cervical lymph-nodes (largest $<1 \mathrm{~cm}^{2}$ ), pharyngeal congestion, and $2 \mathrm{~cm}$ BCM splenomegaly. A reddish mucolopapular rash was present on trunk and arms which subsided in two days and reappeared only after 3 days with high spiking fever.

Chest, CVS, abdominal and neurological examination 
was normal. Her laboratory investigations revealed $\mathrm{Hb}$ of $10.6 \mathrm{gm} / \mathrm{dl}$, TLC of $24.22 / \mathrm{mm}^{2}$ with $84 \%$ polymorphs, with high ESR of $65 \mathrm{~mm} 1 \mathrm{st}$ hour by Westergren's method. KFT was normal. LFT showed mild transaminitis with AST of 56 $\mathrm{U} / \mathrm{L}$ and ALT of $82 \mathrm{U} / \mathrm{L}$ with proteins of $7.58 \mathrm{gm} / \mathrm{dl}$ and albumin of $3.2 \mathrm{gm} / \mathrm{dl}$. ALP was normal. She was extensively worked up for infections. Her repeated blood culture (x4) came sterile. Her urine routine was normal, urine for culture sensitivity was normal. Chest X-ray was normal, USG abdomen was normal except mild splenomegaly. Her Montoux test was negative $(<5 \mathrm{~mm})$. The trans-esophageal echocardiography(TEE) was normal. Bone marrow showed mild iron deficiency anaemia. Her ASO was negative, throat swab for culture sensitivity was sterile. The PBF for MP and viral serology (CMV, EBV, HBsAg and HIV) were negative. The CRP was positive,whileas ANA, anti dsDNA and RF were negative. After extensive workup, we made the diagnosis of "Adult Still's disease" as she was fulfilling most of the criteria laid down by Yamaguchi. ${ }^{5}$ We sent her serum ferritin levels, which came markedly elevated, of the order of $3601 \mathrm{mg} / \mathrm{L}$. She was put on Naproxysn $500 \mathrm{mg}$ TDS and showed marked response. Her fever, rash, arthralgias and myalgias subsided. Her leucocyte count decreased to baseline and was following our department regularly. The patient remained asymptomatic for around one year when in March 2011, she again presented with two weeks' history of high grade fever $\left(40^{\circ} \mathrm{C}\right)$, myalgias, arthralgias and evanescent rash. Her G.P. examination revealed mild pallor, and maculopapular rash on trunk and body which was transient in nature. Her laboratory investigations revealed TLC of $15.37 / \mathrm{mm}^{3}$ with $92 \%$ polymorphs. Platelet count of $413000 / \mathrm{mm}^{3}$, ESR of $84 \mathrm{~mm} 1 \mathrm{st}$ hour(Westergren's method) Her septic screen was negative. Serum ferritin levels were slightly elevated $(586 \mathrm{mg} / \mathrm{L})$. Her ANA, RF, Anti-dsDNA were negative. She was diagnosed as polycyclic Adult Still's disease. She did not respond well to Naprosyn 500mg TDS and was put on steroids (Predinsone $40 \mathrm{mg} /$ day) and she showed a marked response. Her symptoms, signs and lab. parameters improved markedly and is following our outpatient department.

\section{Discussion}

The diagnosis of Adult Still's disease is possible only by recognizing the striking constellation of clinical and laboratory abnormalities. ${ }^{6}$ Moreover, it is a diagnosis of exclusion. One needs to exclude infections and other rheumatological or blood disorders before arriving at the diagnosis of Adult Still's disease. The infective, rheumatological and blood disorders like lymphoproliferative disorder or multiple myeloma were ruled in our patient. Our patient under discussion shared most of the features as laid down for diagnosis of AOSD by Yamaguchi ${ }^{5}$ (Table1).

Fever, rash, arthralgias and sore throat are the most typical clinical features of AOSD. Over $99 \%$ of patients
TABLE 1. Showing diagnostic criteria for AOSD (Yamaguchi) ${ }^{5}$

$$
\text { Major }
$$$$
\text { Minor }
$$

$\begin{array}{ll}\text { Fever }>39^{\circ} \mathrm{C} \text {, lasting }>1 \text { week } & \text { Sore throat } \\ \text { Arthralgias/arthritis lasting }>2 \text { weeks } & \text { Lymphadenopathy or splenomegaly } \\ \text { Typical rash } & \text { Abnormal LFT } \\ \text { WBC }>10,000 \text { with }>80 \% \text { PMN's } & \text { Negative ANA and RF }\end{array}$

Exclusion: Infections, Malignancy, Rheumatic diseases

Diagnosis: Five criteria, at least two major.

(83-91\% sensitivity; $90 \%$ specificity; $70 \%$ PPV; $95 \%$ NPV).

manifest a fever of $\geq 39.0^{\circ} \mathrm{C}$. The highest temperatures are seen in late afternoon or early evening. ${ }^{7}$ In the differential diagnosis of a patient with FUO (fever of unknown origin), maculopapular rashes, arthralgia and sore throat should raise the suspicion of AOS. ${ }^{8-11}$ Febrile spikes are often accompanied by exacerbation of other symptoms like rash, fatigue and arthralgia. ${ }^{12}$ The classic rash is an evanescent, Salmon-pink, maculopapular eruption, which frequently appears during febrile attacks and is predominantly found on the proximal limbs and trunk with rare involvement of face. ${ }^{13}$ Even though $>90 \%$ patients in series reported from West have this characteristic rash, this has been less reported in studies from India, probably due to difficulty in identifying the rash in people with dark skin. ${ }^{14,15}$ This rash can be induced by a minor trauma (Koebner's phenomenon) and dermatographism is a frequently encountered phenomenon in patients with AOSD. Sore throat is known as a cardinal sign of AOSD and may be associated with odynophagia. ${ }^{16}$ Arthralgias and arthritis occur in about $64 \%$ to $100 \%$ of the patients and flare up of joint symptoms occur during the febrile spikes. ${ }^{17}$ The most common joints involved are the knees, wrists, ankles and elbows. Sacro-illiac involvement is uncommon. Destructive arthritis is found in $25 \%$ of cases. Joint fluid aspirate often discloses marked leucocytosis with a PMN predominance. Generalized myalgia is seen in many patients and can be severe and coincide with fever spikes. ${ }^{18}$ Lymphadenopathy develops in $44 \%$ to $90 \%$ of patients with AOSD, and may raise suspicion of lymphoma initially. ${ }^{19,20}$ Hepatosplenomegaly is common in early disease and reflects tissue infiltration by inflammatory cells. ${ }^{21}$ Macrophage activation syndrome (MAS) is a life threatening condition, which is characterized by uncontrolled activation and proliferation of T-lymphocytes and macrophages in bone marrow, RES and CNS. MAS is a dreaded complication of rheumatic diseases, especially systemic onset Juvenile rheumatoid arthritis, has also been reported in AOSD and should be considered in patients with AOSD when it presents with acute febrile illness, hepatosplenomegaly, lymphadenopathy, pancytopenia and increased liver enzymes, coagulopathy, CNS, pulmonary and renal involvement. ${ }^{22}$ The reactive hemophagocytic syndrome (RHS) is a term describing a condition similar to MAS from clinical and also the laboratory stand-point in patients with AOSD. 
Rarely patients of AOSD may develop pleuritis with pleural effusion, peri-carditis, cardiac tamponade, myocarditis, secondary Sjogren's syndrome, aseptic meningitis, panophthalmitis, glomerulonephritis and DIC. ${ }^{23}$ Close to $75 \%$ of patients have elevated liver enzymes. ${ }^{24}$ Occasionally focal hepatitis with feathery degeneration and necrosis of liver may be seen. ${ }^{25}$

The laboratory investigations reflect an exaggerated inflammatory response as evidenced by an elevated ESR and leucocytosis $>15000 / \mathrm{mL}$ with $\geq 80 \%$ PMN, anaemia of chronic disease, hypoalbuminemia and thrombocytosis. Pancytopenia has been described in AOSD associated with hemophagocytic syndrome (HS). ${ }^{26}$ Rheumatoid factor and antinuclear antibody tests are generally negative and if positive, these are of low titers. ${ }^{27}$ High levels of ferritin seem to be characteristic of AOSD. Nearly $70 \%$ of patients have hyper-ferritinemia. Ferritin levels in AOSD are usually higher than those found in other autoimmune or inflammatory diseases. ${ }^{28-30}$ Several cytokines like IL-Ib, IL-18, TNF- $\alpha$ and IL-6 seem to have some role in increasing the production of ferritin. A more specific diagnostic marker may be drop in glycosylated ferritin. In AOSD, decreased glycosylated ferritin, an isoform of ferritin was noted in comparison with other inflammatory diseases. In healthy individuals 50-80\% ferritin is glycosylated, while in inflammatory diseases, it drops to $20 \%-50 \%$ and in AOSD less than $20 \%{ }^{31}$ Hyperferritinemia with a value between 4,000 and $30,000 \mathrm{mg} / \mathrm{dl}$ has been reported in associated with onset and disease activity. ${ }^{32}$

The disease may have a monocyclic (25-30\%), polycyclic (25-30\%) or chronic course (30-50\%). In those with monocyclic course, the disease remits within a year, never to appear again. Those with polycyclic course have intermittent disease and characteristically the intensity tends to be less severe and the duration shorter in the subsequent episodes in comparison to first. Chronic disease is the most disabling, leading to chronic disabling arthritis.

Aspirin or NSAIDS are recommended as the initial treatment in AOSD, but the response rate is as low as $20 \%$ to $25 \% .{ }^{33}$ Liver enzymes should be closely monitored in patients in whom NSAIDS are used. ${ }^{34}$ Since response to NSAID monotherapy is not enough, most patients are treated with corticosteroids in the course of their disease, with an efficacy of upto $95 \%$. Predinisolone should be used for the patients who do not respond to NSAIDS and also for patients suffering from persistent anaemia, peri-carditis, serositis, and marked elevation of liver enzymes. ${ }^{35}$ Steroids are started with dose of 0.5 to $1 \mathrm{mg} / \mathrm{Kg}$ and once the symptoms improve, they are tapered to lowest minimal dose. Relapses and flares may occur once steroids are tapered or stopped, however, they are treated with similar doses and usually respond well. Disease modifying antirheumatic drugs (DMARD) such as Methotrexate (MTX), Azathioprine, cyclophosphamide, and cyclosporine have been used for maintenance therapy and control of disease. ${ }^{36}$ Biological therapies such as anti-TNF- $\alpha$ antibody infliximab, etnercept an anti TFN- $\alpha$ receptor blocker, and others have been reported to be effective in AOSD patients who do not respond to corticosteroids or DMARD. ${ }^{37,38}$ Rituximab (anti- CD20; monoclonal antibody) is a new option in treatment; there are some case reports about its usefulness in AOSD. ${ }^{39}$ In a few care reports, the efficacy of leflunomide was shown in the treatment of AOSD. ${ }^{40}$ Tocilizumab, a humanized anti IL-6 receptor monoclonal antibody of the IgG subclass has been addressed in 2 case reports as being effective for AOSD. ${ }^{41}$

The need to recognize Adult Still's disease as a separate clinical entity has been repeatedly stressed. AOSD, an important cause of FUO, remains a diagnosis of exclusion in the absence of one or more classical features. It is, therefore necessary for physicians to appreciate that AOSD is syndrome that affects adults.

\section{References}

1. Bywaters EG. Still's disease in the adult. Ann Rheum Dis 1971;30:121-33.

2. Efthimiou P, Paik PK, Bielory L. Diagnosis and management of adult onset Still's disease. Ann Rheum Dis 2006; 65:564-72.

3. Meijvis SC, Endema H, Geers AB, Ter Borg EJ. Extremely high serum ferritin levels are diagnostic in adult-onset Still's disease. Neth J Med 2007;65:212-4.

4. Larson EB. Adult Still's disease - recognition of clinical syndrome and recent experience. West J Med 1985; 142: 665-71.

5. Yamaguchi M, Ohta A, Tsunematsu T, et al. Preliminary criteria for classification of adult Still's. Journal of Rheumatology 1992;19:424-30.

6. Esdaile JM, Tannebaum H, Hawkins D. Adult Still's disease. Am J Med 1980;825-30.

7. Cush JJ. Adult onset Still's disease. Bull Rheum Dis 2000;49:1-4.

8. Bambery P, Thomas RJ, Malhotra HS, et al. Adult onset Still's disease: clinical experience with 18 patients over 15 years in Northern India. Ann Rheum Dis 1992;51: 529-32.

9. Mert A, Ozaras R, Tabak F, et al. Fever of unknown origin: a rview of 20 patients with adult onset Still's disease. Clin Rheumatol 2003;22:89-93.

10. Crispin JC, Martinez-Bonos D, et al. Adult onset Still's disease as the cause of fever of unknown origin. Medicine (Baltimore) 2005;84:331-7.

11. Owlia MB. Clinical spectrum of connective tissue disorders. J Indian Acad Community Med 2006;7:217-24.

12. Cush JJ, Medsger TA Jr, Christy WC, Herbert DC, Cooperstein LA, et al. Adult onset Still's disease: Clinical cause and outcome. Arthritis Rheum 1987;30:186-94.

13. Ridgway HA. Adult onset Still's disease. Jr Soc Med 1982;75:474-6. 
14. Pouchot J, Sampalis JS, Beardet F, et al. Adult onset Still's disease: manifestations, disease course and outcome in 62 patients. Medicine (Baltimore) 1991;70: 118-36.

15. Singh YN, Adya CM, Kumar A, Malaviya AN, et al. Adult onset Still's disease in India. $\mathrm{Br} J$ Rheumatol 1992;31:417-9.

16. Kelly J, Chowiencayk P, Gibson T. Sore throat and hyperferritinemia. JR Soc Med 2001;94:400-1.

17. Wouters JM, Vande Putte LB. Adult-onset Still's disease: clinical and laboratory features, treatment and progress of 45 cases. QJ Med 1986;61:1055-65.

18. Ohta A, Yamaguchi M, Tsunematsu T, et al. Adult Still's disease: a multicenter survey of Japanese patients. $J$ Rheumatol 1990;17:1058-63.

19. Reginato AJ, Schumachar HR Jr, Baker DG, et al. Adult onset stills disease: experience in 23 patients and literature review with emphasis on organ failure. Semin Arthritis Rheum 1987;17:39-57.

20. Valente RM, Banks PM, Conn DL. Characterisation of lymphnode histology in adult onset Still's disease. J Rheumatol 1989;16:349-54.

21. Uppal SS, Al-Mutairi M, Hayat S, et al. Ten years of clinical experience with adult onset Still's disease: is the outcome improving? Clin Rheumatol 2007;26:1055-60.

22. Owalia MB, Soleimani H, et al. Macrophage activation syndrome (MAS) and thrombotic thrombocytopenic purpura (TTP): are they from a single spectrum? J Indian Acad Community Med 2005;6:337-40.

23. Arai Y, Handa T, Mitani K. Adult onset Still's disease presenting with disseminated intravascular coagulation. Rinosho Ketsueki 2004;45:316-8.

24. Ohta A, Yamaguchi M, Kaneoka H, et al. Adult Still's disease: review of 228 cases from the literature. $J$ Rheumatol 1987;14:1139-46.

25. Esdaile JM, Tannenboum H, et al. Hepatic abnormality in adult onset Still's disease. J Rheumatol 1979;6:673-9.

26. Pamuk ON, Pamuk GE, Usta U, et al. Hemophagocytic syndrome in one patient with adult-onset Still's disease: presentation with febrile neutropenia. Clin Rheumatol 2007;26:797-800.
27. Pouchot J, Sampalis JS, Beaudet F, et al. Adult Still's disease: manifestations disease course, and outcome in 62 patients. Medicine (Baltimore) 1991;70:118-36.

28. Meijvis SC, Endeman H, Gears AB, et al. Extremely high serum ferritin levels as diagnostic tool in adultonset Still's disease. Meth J Med 2007;65:212-4.

29. Cagatay Y, Gul A, Cagatay A, et al. Adult onset Still's disease. Int J Clin Prac 2009;63:1050-5.

30. Kelly J, Chowiencayk P, Gibson T. Sore throat and hyperferritinemia. JR Soc Med 2001;94:400-1.

31. Fardet L, Coppo P, Kettanalu A, et al. Low glycosylated ferritin: a good marker for the diagnosis of hemophagocytic syndrome. Arthritis Rheum 2008;58:1521-7.

32. Van Reath C, Le Moel G, Lasne Y, et al. Serum ferritin and isoferritins and tools of diagnosis of active adult Still's disease. J Rheumatol 1994;21:890-5.

33. Kadar J, Petrovica E. Adult-onset Still's disease. Best Pract Res Clin Rheumatol 2004;15:263-75.

34. Chandran V, Aggarwal A. Adult-onset Still's disease. J Indian Rheumatol Assoc 2002;10:19-21.

35. Van de Putte LB, Wouters JM. Adult onset Still's disease. Baillieres Clin Rheumatol 1991;29:396-8.

36. Kraetsch HG, Antoni C, Kalden JR, et al. Successful treatment of a small cohort of patients with adult onset Still's disease with infliximab; first experiences. Ann Rheum Dis 2001;60:155-7.

37. Furst DE, Breedveld FC, Kalden JR, et al. Updated consensus on biological agents for the treatment of rheumatic disorders. Ann Rheum Dis 2007;66:112-22.

38. Covagna L, Caporali R, Epis O, et al. Infliximixab in the treatment of adult Still's disease refractory to conventional therapy. Clin Exp Rheumatol 2001;19:329-32.

39. Ahmad-Simab K, Lamprecht P, Jankowiak C, et al. Successful treatment of refractory adult onset of Still's disease with rituximab. Ann Rheum Dis 2006;65:1117-8.

40. Pirildar T. Treatment of adult onset of Still's disease with leflunomide and chloroquine combination in two patients. Clin Rheumatol 2003;22:157.

41. Nakahara H, Hima T, Yoshio-Hoshino N, et al. A case report of a patient with refractory adult-onset Still's disease who was successfully treated with tocilirumab over 6 years. Mod Rheumatol 2009;19:69-72. 